\section{International Scientific Journal Theoretical \& Applied Science}

\author{
p-ISSN: 2308-4944 (print) e-ISSN: 2409-0085 (online) \\ Year: 2015 Issue: 05 Volume: 25 \\ Published: $30.05 .2015 \quad \underline{\text { http://T-Science.org }}$
}

Inna Aleksandrovna Serebryanik Candidate of technical sciences, Associate Professor of the

Department of World economy, Irkutsk National Research Technical University, Russia nasamolet@yandex.ru

SECTION 12. Geology. Anthropology.

Archaeology.

\title{
INDIAN MICA: A BRILLIANT PAST AND AN UNCERTAIN FUTURE
}

Abstract: The article discusses the history of development of the mica market in India. Presents the problems of the mica industry in the India. Analyzed India's role as a major supplier of mica in the world.

Key words: mica, India, mica production, mica, USSR.

Language: Russian

Citation: Serebryanik IA (2015) INDIAN MICA: A BRILLIANT PAST AND AN UNCERTAIN FUTURE. ISJ Theoretical \& Applied Science 05 (25): 5-8.

Soi: http://s-o-i.org/1.1/TAS*05(25)2 Doi: crossef http://dx.doi.org/10.15863/TAS.2015.05.25.2

\section{ИНДИЙСКАЯ СЛЮДА: БЛЕСТЯЩЕЕ ПРОШЛОЕ И НЕЯСНОЕ БУДУЩЕЕ}

Аннотация: В статье рассмотрена история развития рынка слюды в Индии. Представлень проблемы слюдяной отрасли в Индии. Проанализирована роль Индии, как основного поставщика слюды в мире.

Ключевые слова: слюда, Индия, слюдяное производство, мусковит, СССР .

В 1990-х годов Правительство Российской Федерации предоставило уникальный шанс индийским поставщикам слюды. Оно снизило пошлины на ввоз. Россия открыла рынок для самого крупного поставщика слюды в мире. Такой шаг, по сути, «поставил крест» на российском слюдяном производстве. Местные производители стали закрываться один за другим, не выдерживая ценовой конкуренции с дешевой индийской слюдой.

Индия является лидером в добыче листового мусковита. Индийский мусковит рубиновый (применим в электротехнической промышленности) и зеленый (применим в оптике). Индийский мусковит знаменит отличным качеством.

На три индийских штата приходится 95\% добываемой слюды:

1. Андхра-Прадеш (72,5\%); В штате АндхраПрадеш проходит уникальный слюдяной пояс 100 км длиной и 25 км шириной.

2. Раджасхан $(15,6 \%)$;

3. Джаркханд $(10,9 \%)$.

Также слюду добывают в Бихаре (0,9\%).

При этом нет точных данных о запасах слюды. Можно лишь привести примерные данные в 532000 тонн. Возможно, связано это с тем, что наличие слюды в природе не обусловлено какими-либо правилами и закономерностями. Тем не менее, Индия является мировым лидером по запасам природной слюды, Россия занимает второе место, Индия характеризует российские запасы как средние. Запасы слюды в США индийские специалисты называют малыми.

Индия поставляет более $60 \%$ всей слюды в мире. Индийская слюда продается в Китай (более 50\%), Японию (19\%), США (17\%), Великобританию (7\%), Германию, Россию, Францию, Чехию и др. [1].

Индия использовала слюду с незапамятных времен. Она заменяла стекло в фонарях, ее украшали одежду, ее использовали в работах художники. Даже в индийской медицине порошок слюды считался хорошим тонизирующим средством и использовался в чистом виде, а также в сочетании с другими компонентами.

Сегодняшнее применение слюды достаточно широко (Рис. 1). 


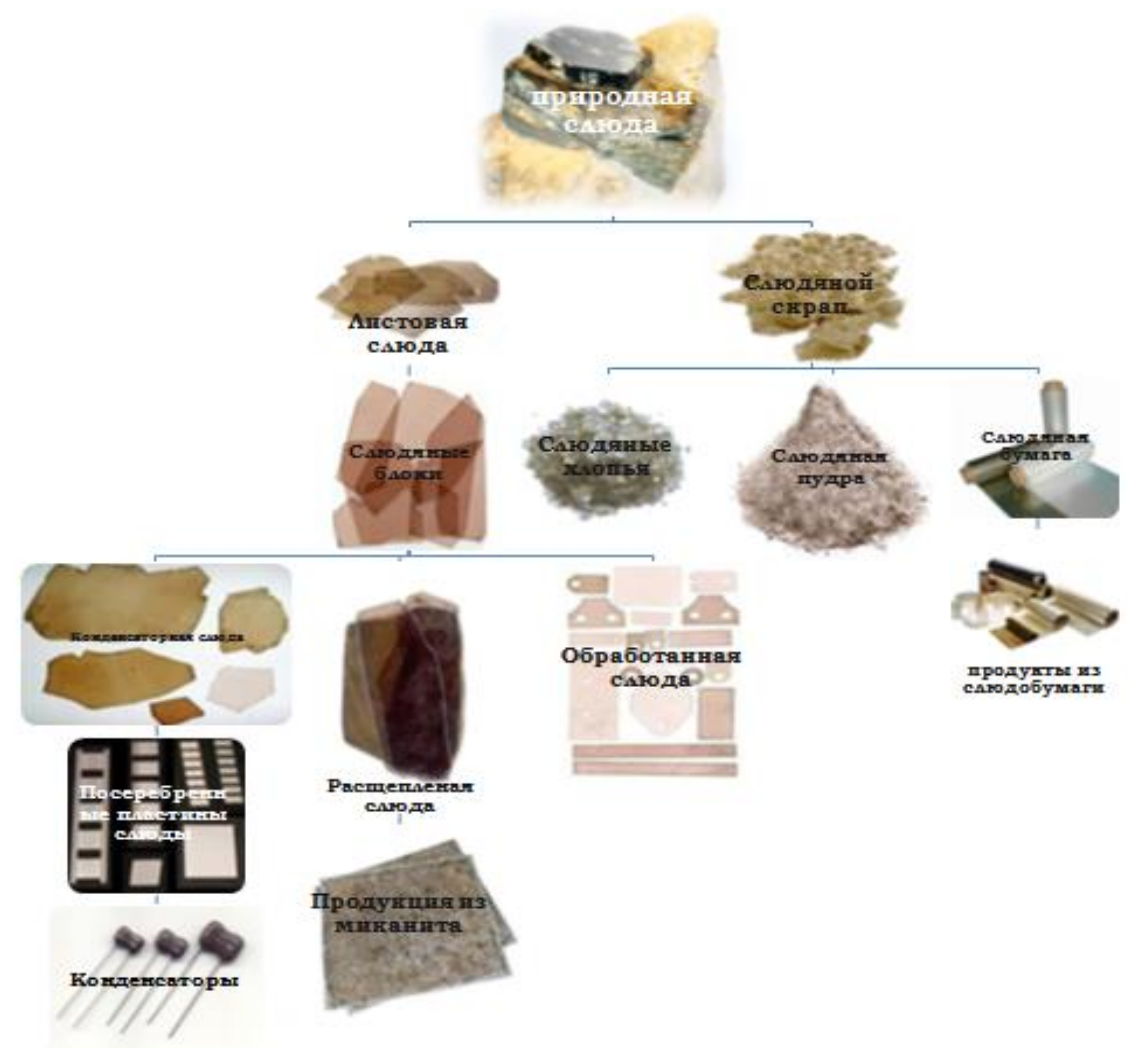

Рисунок 1 - Схема обработки слюды с получение готового продукта.

Производители говорят о существовании более 300 видов продукции, содержащих слюду в том или ином виде.

Традиционное использование слюды - это электротехника и оптика, одно сегодня можно говорить о широких возможностях применения данного минерала. Это и строительство, где слюда используется в качестве наполнителя для смесей, автомобильное производство, где слюда выступает добавкой в изделия из резины, пластика, лаков и красок. Слюда также прекрасный почвоулучшитель.

Часто блеск слюды является ключевым фактором. Сегодня ни один производитель косметики не обходится без такого минерала, как слюда (Рис. 2).

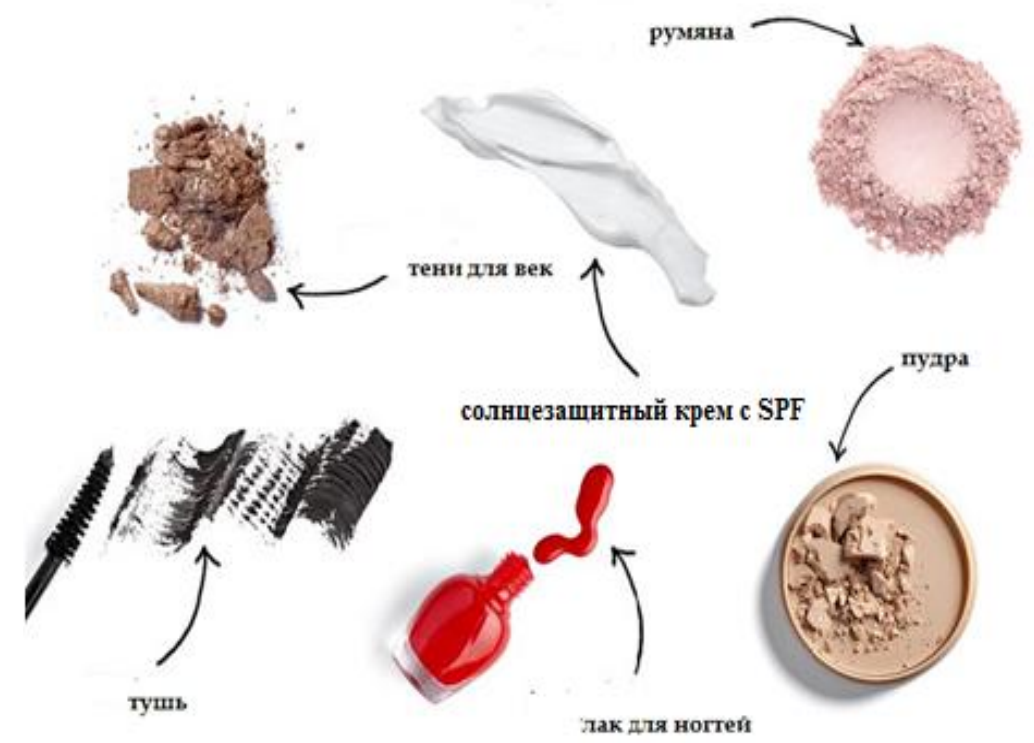

Рисунок 2 - Косметические средства, содержащие слюду.

ISPC Industry \& Technology Europe,

Lyon, France 
Огромный спрос на слюду связан с тем, что сейчас популярностью пользуется натуральная косметика, частью которой и является слюда. Однако слюдодобыча в Индии не попадает под определение «блестящая».

Официальные данные гласят, что Индия производит в год 15000 тонн слюдяного скрапа. При этом экспорт слюды составляет более 130000 тонн. Такое расхождение говорит о том, что добыча слюды в Индии находится в тени, являясь незаконной. Ведут ее, в основном в тех шахтах, которые по тем или иным причинам были закрыты. Создаются длинные цепочки поставок, при этом покупатель не знает, откуда реально получает товар - от официального производителя или от «серого». Незаконное производство задействует низкоквалифицированных рабочих, а также их малолетних детей, и это при том, что по индийским законам детский труд в горнодобывающей промышленности запрещен [10]. Правозащитники говорят о практике использования труда пятилетних детей в слюдяных шахтах [3]. Производители говорят о том, что проблемы незаконной добычи можно было бы решить, если бы Правительство предоставляло больше лицензий. Однако Правительство предпочитает не видеть проблему, которой уже много лет. Уже в далеком 1925 году 50\% слюды добывалось незаконно [2; 5].

Губительное действие на слюдяной рынок Индии оказало создание Mica Trading Corporation (МІTCO) в 1972 году. МІТСО должен был регулировать экспорт слюды из Индии, вырабатывая общие принципы и правила. Каждая компаний должна была предоставлять МITCO образцы продаваемой слюды, прежде, чем продавать их. Созданная организация на практике оказалась коррупционной. Компании получали разрешение на продажу в обмен на денежное вознаграждение. МІТСО предпочитала не обращать внимание на ценовые колебания, которые были выгодны отдельным бизнесменам. И что хуже всего, МІТСО сосредоточило в своих руках 60\% каналов сбыта. Только в 1992 году, MITCO по сути была национализирована, ее работа стала прозрачной и коррупция была практически уничтожена [4].

Добыча слюды в Индии началась в 1887 году. В 1940 году разрабатывалось 240 месторождений. В 1950-е годы произошла технологическая революция. Все шахты были электрифицированы. Бензиновые двигатели заменили электрические. Период 1950-1960-х годов считаются золотым веком в слюдодобыче, несмотря на то, что рынок в это время начал падать. Если в 1944 году добыли 596 тонн слюды, то в 1961 году - 7000 тонн. Однако уже 1988 году слюды добыли лишь 1550 тонн. За период Второй Мировой войны количество шахт сократилось до 144. В 1974 году их осталось лишь 30, в 1997 году - 14. Среди причин сокращения производства стоит выделить такие как, падение рынка, пессимистические взгляды Правительства на слюдодобычу, а также неопределенность запасов слюды.

В 2012-2013 гг. производство природной слюды выросло на 34\% по сравнению с прошлым годом и составило 1255 тонн (Рис. 3), при этом количество используемых месторождений уменьшилось с 35 до 32 [8].

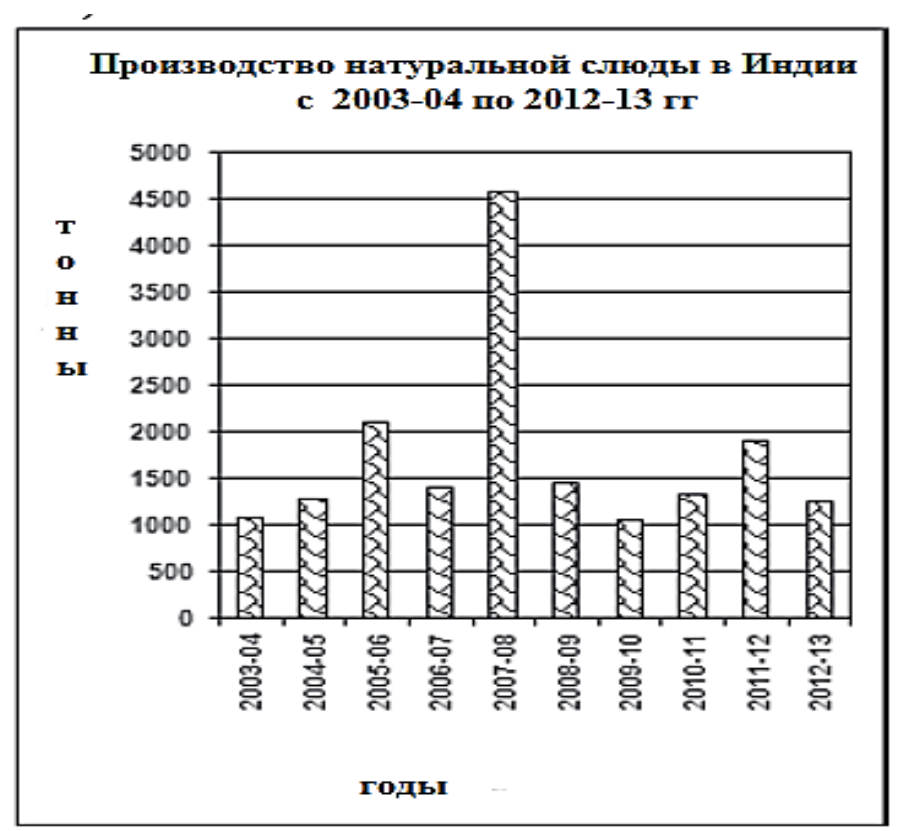

Рисунок 3 - Производство натуральной слюды в Индии с 2003-04 по 2012-13 гг. [9]. 
Шесть основных производителей дают 71\% добычи [8]:

1. Dwarakananad M. Reddy \& Others;

2. Mahanta Mica Mines;

3. Meenakshi Sundaram;

4. Seetharama Mining Co;

5. Yasodha Krishna Mica.

Рынок слюды в Индии считается падающим уже порядка 30 лет. Экспортный рынок для индийской слюды сокращается. Например, США накапливали индийскую слюду с 1940-х годов. Америка использовала ее в производстве деталей для военной техники. В результате запасы оказались так велики, что сегодня США отправляет когда-то купленную слюду обратно в Индию на переработку [9]. Кроме того, появились альтернатива - искусственная слюда. Она дешева и имеет отличные изоляционные свойства.
Распад СССР лишил Индию крупного покупателя слюды. Советы приобретали у Индии так называемый рубиновый мусковит, имеющий оптимальные электрические характеристики.

Производство слюды в этой стране превышает спрос на нее. Тем не менее, индийская слюда является жизненно важной для многих производств. Руководство страны рекомендует местным производителям ориентироваться на автомобильную отрасль, которой необходима слюда для создания автомобильных красок и лаков. Также производители должны пойти по пути улучшения качества продукта. Качество в данном случае - это его чистота, т.е. отсутствие разного рода посторонних включений. Возможно, Индии стоит сделать предметом экспорта не столько природную слюду, сколько продукты с добавленной стоимостью, такие как миканиты, слюдобумагу и другие.

\section{References:}

1. Arnab Kumar Hazra (2013) Development of Indian Mining Industry - The Way Forward Non-Fuel minerals. Federation of Indian Chambers of Commerce \& Industry. 2013. -120 p.

2. Barrier Miner (1925) (Broken Hill, NSW : 1888 - 1954), Saturday 3 January 1925, pp. 3.

3. Ben Doherty, Sarah Whyte (2014) India's mica mines: The shameful truth behind mineral make-up's shimmer. //Sydney morning Herald. 19 jan 2014.

4. (2015) The Indian Bureau of Mines (IBM) Available: http://www.ibm.nic.in - (Accessed: 03.05.2015).

5. (1920) INDIAN MICA INDUSTRY.; Scientific Methods of Mining Are Replacing Primitive Ones. //The New York Times - 7 November, 1920.

6. (2015) Indian Minerals. Yearbook 2013 (PartIII : Mineral Reviews) 52nd Edition. MICA. Indira Bhavan, Civil Lines, 2015.
7. Joel Katz (2015) Artisanal and small-scale mining in Asia-Pacific region. Case study series. Available: http://www.birsa.in/wpcontent/uploads/2010/07/artisanal-and-smallscale-mining-in-asia.pdf (Accessed: 03.05.2015).

8. Kumar Sanjay (1993) Problems and Prospects of Mineral Industry in India: A Study of Mica Industry. - India, 1993. 213p.

9. Sudhakar Rao (1997) Impact of Erratic Rainfall and mica mines in a south Indian village. Kamla Rai, 1997.

10. (2015) Ugly truth behind global beauty industry. Aljazeera. Available: http://www.aljazeera.com/indepth/features/2014 /09/ugly-truth-india-global-beauty-industrycosmetics-mica-201499101422805960.html (Accessed: 03.05.2015). 